\begin{tabular}{|c|c|c|}
\hline Dinamika Journal, Vol. 1 No. 4, 2019 \\
ISSN ONLINE : 2686-2158
\end{tabular}

\title{
PENINGKATAN KOMPETENSI KADER DAN MONITORING TERHADAP FAKTOR RISIKO PTM (PENYAKIT TIDAK MENULAR) DESA KARANGGINTUNG, KECAMATAN SUMBANG, KABUPATEN BANYUMAS
}

\section{Gumintang Ratna Ramadhan ${ }^{1 *}$, Dika Betaditya ${ }^{1)}$, Yovita Puri Subardjo ${ }^{1)}$, Friska Citra Agustia ${ }^{1)}$}

\author{
${ }^{1}$ Program Studi Ilmu Gizi, Fakultas Ilmu-ilmu Kesehatan, Universitas Jenderal Soedirman, \\ Purwokerto, Indonesia \\ *Corresponding author: gumintang_intang@yahoo.com
}

Received 30 September 2019; Accepted 3 December 2019; Available online 16 December 2019

\begin{abstract}
Abstrak
Saat ini telah terjadi pergeseran penyebab kematian dari penyakit menular ke Penyakit Tidak Menular (PTM). Posbindu PTM bertujuan untuk meningkatkan partisipasi masyarakat dalam deteksi dini, pemantauan dan tindak lanjut faktor risiko PTM. Untuk dapat mencapai tujuan tersebut, diperlukan peran besar dari kader. Kegiatan ini bertujuan meningkatkan kompetensi kader posbindu mengenai pengetahuan dan keterampilan kader posbindu dalam memonitoring faktor risiko penyakit tidak menular di Desa Karanggintung Kecamatan Sumbang. Metode yang digunakan dalam kegiatan ini adalah metode partisipatif aktif artinya kegiatan melibatkan khalayak sasaran untuk berperan aktif dalam kegiatan ini dengan tujuan agar terjadi peningkatan pengetahuan dan keterampilan khususnya kader posbindu. Berdasarkan hasil evaluasi dan pengamatan terjadi peningkatan keterampilan yaitu hampir seluruh kader benar dalam melakukan pengukuran, pengisian buku monitoring dan sudah dilakukan sesi konsultasi. Salah satu kader juga cukup percaya diri dalam melakukan pengukuran menggunakan alat autocheck. Dengan demikian dapat disimpulkan bahwa pelaksanaan pelatihan di Posbindu Sehat Mulia III Desa Karanggintung Kecamatan Sumbang Kabupaten Banyumas dapat meningkatkan kompetensi kader terlihat dari meningkatnya pengetahuan dan keterampilan para kader sehingga akan berdampak pada optimalisasi monitoring faktor risiko penyakit tidak menular secara dini.
\end{abstract}

Kata kunci : Kader, Posbindu, Penyakit Tidak Menular, Pengetahuan, Keterampilan

\begin{abstract}
Currently there has been a change in causes from infectious diseases to non-communicable diseases (NCD). Posbindu NCD aims to increase community participation in early detection, monitoring and follow-up of NCD risk factors. To be able to achieve these objectives, a large role for cadres is needed. This activity increases the competence of posbindu cadres about the knowledge and skills of posbindu cadres in monitoring risk factors for non-communicable diseases in Karanggintung Village, Sumbang District. The method used in this activity is a participatory method that refers to activities that involve the intended audience for active
\end{abstract}


activities with the aim that an increase in knowledge and special skills in post cadres. Based on the results of evaluations and evaluations that occur skill enhancement is that most cadres are correct in assessing, filling in the monitoring book and having conducted a consultation session. One of the cadres was also quite confident in conducting an assessment using the autocheck tool. Thus, the implementation training in Posbindu Sehat Mulia III Karanggintung Village, Sumbang District, Banyumas Regency, which can improve competence as seen from the cadres knowledge and skills so that it will be improved in optimizing early non-communicable risk factor monitoring.

Keywords: cadres, posbindu, non-communicable disease, knowledge, skills

\section{PENDAHULUAN}

Saat ini telah terjadi pergeseran penyebab kematian dari penyakit menular ke Penyakit Tidak Menular (PTM). Kejadian PTM seperti hipertensi dan diabetes mellitus di dunia diperkirakan terus mengalami peningkatan. Prevalensi hipertensi dan diabetes mellitus (DM) di Indonesia yaitu $25.8 \%$ dan $2.1 \%$ dimana penyakit tidak menular tersebut adalah bagian dari 10 penyebab kematian terbesar di Indonesia (Balitbangkes, 2013). Di lain sisi PTM menimbulkan kesakitan dan kematian yang merugikan penderita, keluarga dan negara dari sisi sosial maupun ekonomi. Pemerintah Indonesia telah menangkap fenomena tersebut dan mendirikan wadah yang disebut Pos Pembinaan Terpadu Penyakit Tidak Menular (Posbindu PTM). Posbindu PTM merupakan peran serta masyarakat dalam melakukan kegiatan deteksi dini dan pemantauan faktor risiko PTM utama yang dilaksanakan secara terpadu, rutin, dan periodik. Sasaran Posbindu PTM yaitu masyarakat sehat, masyarakat berisiko dan masyarakat dengan PTM berusia 15 tahun ke atas (Direktorat Pengendalian PTM, 2014).

Kasus PTM sebenarnya dapat dicegah dengan mengendalikan faktor risiko, yaitu gaya hidup yang meliputi kebiasaan merokok, diet yang tidak sehat, kurang aktivitas fisik, dan konsumsi alkohol. Posbindu PTM bertujuan untuk meningkatkan partisipasi masyarakat dalam deteksi dini, pemantauan dan tindak lanjut faktor risiko PTM. Untuk dapat mencapai tujuan tersebut, diperlukan peran besar dari kader. Seorang kader harus memahami pengertian dan tugasnya sebagai kader, serta tujuan pokok dan fungsi pengadaan posbindu itu sendiri. Seorang kader juga harus memiliki keterampilan yang mendukung tugasnya sebagai kader kesehatan, semisal terampil dalam melakukan antropometri, pengukuran menggunakan autocheck dan spigmomanometer, atau memberikan konseling. Kader posbindu juga mempunyai peran sebagai pemberi informasi kesehatan kepada masyarakat juga sebagai penggerak masyarakat untuk datang ke posbindu.

Posbindu Sehat Mulia III yang terletak di desa Karanggintung, Kecamatan Sumbang, Kabupaten Banyumas adalah salah satu posbindu yang sudah empat tahun berdiri tetapi sampai sekarang kurang aktif dan berkembang. Posbindu PTM ini didukung tenaga kader yang berjumlah 8 orang dengan latar belakang pendidikan sekolah menengah atas (SMA), D3 serta S1, dinilai akan mampu menjadi modal yang cukup untuk menjadikan Posbindu ini berkembang menjadi posbindu yang ideal. Namun sayangnya, seluruh kader di Posbindu ini tidak ada yang memiliki latar belakang pendidikan bidang kesehatan sehingga dalam melaksanakan tugasnya sebagai kader, mereka hanya sesuai instruksi dan pelaksanaan Posbindu bergantung pada bidan desa. Apabila bidan desa berhalangan hadir maka kegiatan Posbindu tidak dilaksanakan, sehingga dapat dikatakan keterampilan dan pemahaman akan tujuan pokok dan fungsi posbindu dari para kader ini masih kurang.

Melihat kondisi tersebut, tim pengabdi berinisiatif untuk mengadakan pelatihan guna meningkatkan pengetahuan dan keterampilan kader terkait pengukuran antropometri secara benar, cara menggunakan alat ukur gula darah, kolesterol, asam urat, spigmomanometer, 
menghidupkan kembali fungsi pelayanan dari setiap meja di posbindu serta menjelaskan fungsi dan cara penggunaan buku monitoring faktor risiko PTM. Hida dan Mardiana (2011) melaporkan tentang efektivitas metode pelatihan kader posyandu dalam meningkatkan pengetahuan dan keterampilan.

Kegiatan ini diharapkan mampu membuka wawasan dan keterampilan para kader posbindu terkait fungsi meja di posbindu, pengukuran antropometri dan kesehatan, serta fungsi buku monitoring faktor risiko. Dalam kegiatan ini, tim pengabdi menyertakan seluruh kader Posbindu.

\section{METODE PELAKSANAAN}

Kegiatan ini dilaksanakan selama 8 bulan di Posbindu Sehat Mulia III Desa Karanggintung, Kecamatan Sumbang, Kabupaten Banyumas. Metode yang digunakan dalam kegiatan ini adalah metode partisipatif aktif artinya kegiatan melibatkan khalayak sasaran untuk berperan aktif dalam kegiatan ini dengan tujuan agar terjadi peningkatan pengetahuan pada masyarakat serta kader dan terjadi peningkatan keterampilan khususnya pada kader posbindu, dengan didampingi oleh tim pengabdi yang merupakan tim penerapan IPTEKS yang berperan sebagai pemberdaya, penyuluh dan fasilitator.

Adapun tahapan pelaksanaan kegiatan terbagi menjadi beberapa tahapan sebagai berikut:

1. Tahap Persiapan

Tahapan persiapan meliputi,

a) Koordinasi rencana kegiatan dengan mitra mengenai jenis kegiatan dan materi yang akan disampaikan.

b) Koordinasi waktu dan lokasi rencana kegiatan penyuluhan dan pelatihan

c) Penyusunan dan pencetakan materi kegiatan (penyuluhan, pelatihan) meliputi modul, leaflet.

d) Pembelian sarana dan prasarana yang diberikan sekaligus digunakan untuk simulasi dan praktek keterampilan prosedur pemantauan faktor risiko PTM.

2. Tahap Pelaksanaan

a) Sebelum dimulai pelatihan dilakukan pre test terlebih dahulu untuk evaluasi kegiatan

b) Penyuluhan tentang PTM, faktor risiko, dampak dan pengendalian PTM

c) Pelatihan keterampilan mengenai cara pengukuran antropometri yang benar meliputi prosedur standar penimbangan berat badan, mengukur tinggi badan, gula darah, kolesterol total, lingkar perut lalu mencatat dan menginterpretasikan tren hasil pengukuran setiap bulan yang dikemas dalam konsultasi gizi.

d) Penyerahan sarana dan prasarana yang digunakan untuk pemantauan faktor risiko PTM, meliputi :

1) Timbangan Injak Digital

2) Alat Pengukur Tinggi Badan (Mikrotoise)

3) Alat ukur lingkar perut (pita metlin)

4) Alat untuk mengukur gula darah, kolesterol, dan asam urat (autocheck) dan spigmomanometer digital

5) Mencetak dan memperbanyak buku monitoring Faktor Risiko PTM untuk masyarakat

e) Post test dilakukan setelah rangkaian kegiatan pelatihan selesai 


\section{HASIL DAN PEMBAHASAN}

\section{a. Focus Grup Discussion (FGD) dengan Kader Posbindu}

Kegiatan program penerapan Ilmu Pengetahuan, Teknologi, dan Seni (IPTEKS) sudah dilaksanakan 100\% di Posbindu Sehat Mulia III Desa Karanggintung Kecamatan Sumbang Kabupaten Banyumas Jawa Tengah. Terdapat 8 orang kader yang berpartisipasi dalam kegiatan ini. Seluruh kader berjenis kelamin wanita yang merupakan ibu rumah tangga dengan rentang usia 30-40 tahun dan berdomisili di wilayah RW III Desa Karanggintung. Kegiatan ini diawali dengan melakukan Focus Grup Discussion (FGD) dengan para kader untuk menggali permasalahan yang dihadapi serta merencanakan kegiatan pelatihan dan pendampingan dalam mengatasi upaya tersebut. Dengan FGD tim pengabdi dapat mengetahui persepsi, opini, dan sikap kader terhadap pemantauan faktor risiko PTM (Paramita et al., 2013).

Dari hasil FGD dengan para kader didapatkan beberapa permasalahan yaitu tidak tersedianya fasilitas yang memadahi pada saat kegiatan posbindu. Selama ini alat-alat yang digunakan adalah milik bidan desa dan yang mengukur adalah bidan tersebut, sehingga selama ini para kader hanya melakukan kegiatan pada meja 1 yaitu registrasi dan meja 3 yaitu pengukuran berat badan dan lingkar perut.

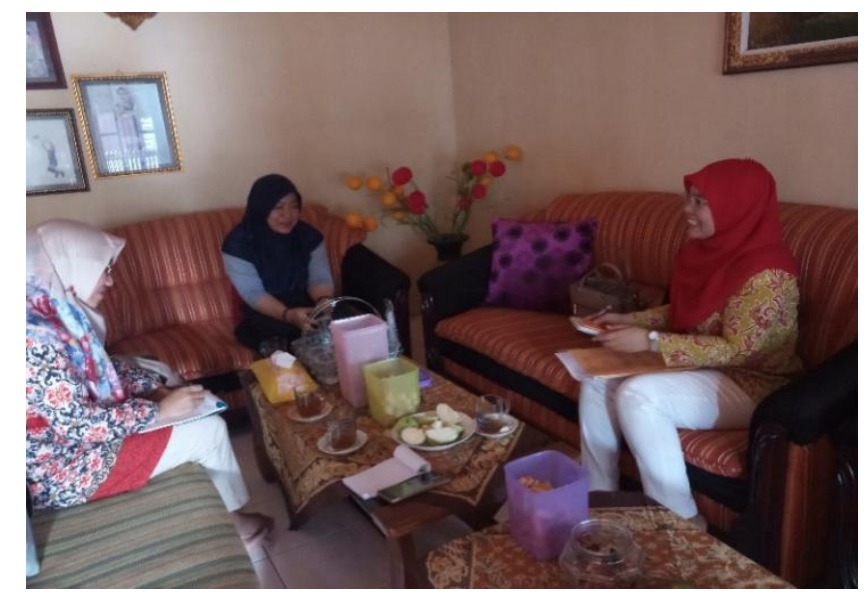

Gambar 1. FGD dengan ketua kader dan anggota kader

Kader tidak pernah melakukan pengukuran tekanan darah, gula darah, kolesterol, asam urat menggunakan alat spigmomanometer dan autocheck karena belum memahami cara dan prosedur menggunakan alat tersebut dikarenakan tidak tersedianya alat tersebut di posbindu Sehat Mulia III, sehingga pada kesempatan ini tim pengabdi akan memfasilitasi pengadaan sarana tersebut dan memberikan pengetahuan cara menggunakan alat tersebut agar para kader terampil tanpa bergantung dari bidan desa.

Pengisian hasil pengukuran peserta posbindu selama ini juga masih dicatat dalam selembar kertas yang berisi kolom-kolom, tidak dicatat dalam buku Monitoring Faktor Risiko Penyakit Tidak Menular yang dikeluarkan oleh Dinas Kesehatan. Hal ini menyebabkan pemantauan faktor risiko tidak dapat dideteksi secara dini karena tidak terdapat catatan yang lengkap pada setiap kegiatan pengukuran, sehingga pada kegiatan IPTEKS ini tim pengabdi berinisiatif untuk memberikan buku monitoring kepada masyarakat dan memberikan pelatihan kepada para kader bagaimana cara mengisi buku monitoring serta tips-tips wawancara/konseling yang baik dan benar. 


\section{b. Peningkatan Pengetahuan para Kader Posbindu dan Masyarakat Peserta Posbindu}

Agar kualitas program pemantauan faktor risiko penyakit tidak menular di posbindu Sehat Mulia III setiap bulan meningkat maka optimalisasi posbindu terkait hal tersebut mutlak di perlukan, dalam hal ini kader posbindu memiliki peran sentral keberhasilan program pemantauan faktor risiko PTM. Berkaitan dengan hal tersebut maka perlu dilakukan serangkaian kegiatan dalam rangka optimalisasi posbindu PTM program pengabdian penerapan IPTEKS ini melalui beberapa kegiatan antara lain peningkatan pengetahuan kader dan masyarakat peserta posbindu dengan cara memberikan penyuluhan.

Penyuluhan merupakan kegiatan pendidikan yang dilakukan dengan cara menyebarkan pesan, menanamkan keyakinan sehingga masyarakat tidak saja sadar, tahu dan mengerti tetapi juga mau dan bisa melakukan suatu anjuran yang ada hubungannya dengan pesan yang disampaikan (Effendi, 2008). Materi atau pesan yang disampaikan pada kesempatan ini meliputi pengetahuan tentang PTM, faktor risiko, dampak, dan pengendalian PTM, serta makanan sehat bagi penderita PTM.

Penyuluhan dilakukan di balai desa Karanggintung dan diikuti sekitar 60 peserta. Penyuluhan diberikan oleh Friska Citra Agustia, S.TP., M.Sc dengan judul "Makanan Sehat untuk Penderita Diabetes, Asam Urat, Kolesterol, dan Hipertensi". Inti dari penyuluhan ini yaitu agar para kader dan masyarakat tahu tentang makanan-makanan yang dianjurkan dan dihindari apabila berisiko menderita penyakit tidak menular dan diharapkan dapat menerapkan pola makan yang bergizi beragam dan berimbang.

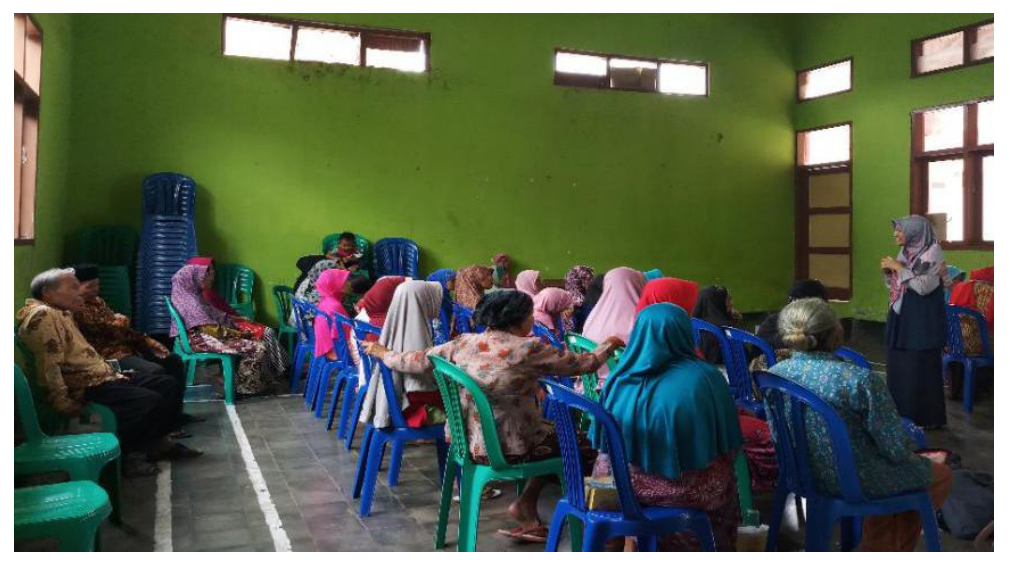

Gambar 2. Penyuluhan tentang makanan sehat untuk penderita PTM

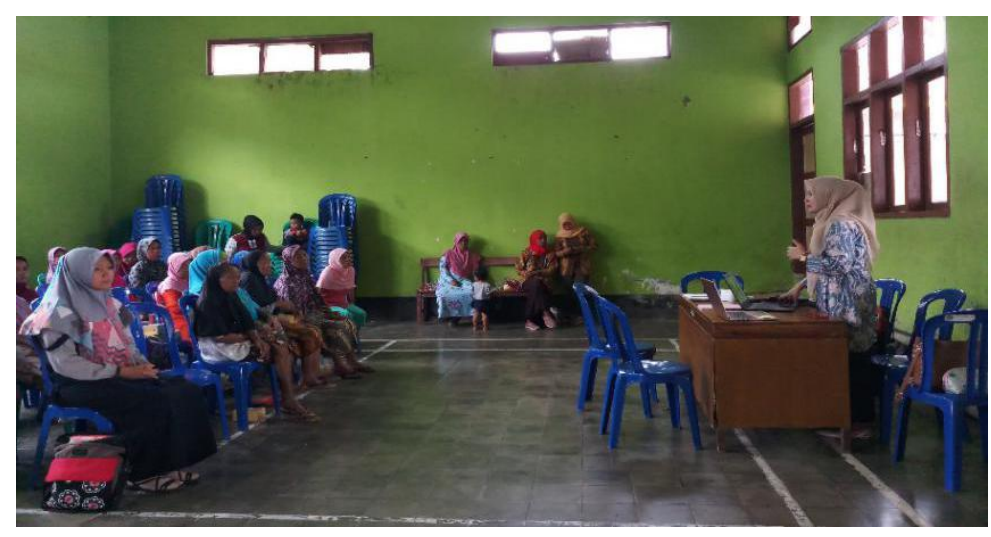

Gambar 3. Penyuluhan tentang faktor risiko gaya hidup terhadap kejadian PTM 
Penyuluhan kedua mengenai "Faktor Risiko Gaya Hidup terhadap Kejadian Penyakit Tidak Menular (PTM)" yang disampaikan oleh Dika Betaditya, S.Gz., MPH. Dalam penyuluhan ini dijelaskan tentang aktifitas-aktifitas yang seharusnya dilakukan agar terhidar dari risiko penyakit tidak menular dan melakukan skrining serta waspada apabila terjadi beberapa faktor risiko PTM seperti peningkatan tekanan darah, kelebihan berat badan, kadar glukosa darah tinggi, atau kadar kolesterol tinggi.

Dalam kegiatan penyuluhan ini diharapkan para kader dan masyarakat menjadi tahu tentang makanan yang seharusnya dikonsumsi agar terhindar dari PTM dan gaya hidup yang sebaiknya dilakukan seperti tidak merokok dan sering melakukan aktifitas fisik. Pada saat kegiatan penyuluhan tim pengabdi juga memberikan makanan tambahan untuk peserta posbindu.

\section{c. Peningkatan Keterampilan para Kader Posbindu}

Sebelum para kader diajarkan mengenai keterampilan menggunakan alat-alat dan cara pengisian buku monitoring dilakukan pretest mengenai surveilans atau batasan-batasan faktor risiko penyakit tidak menular dengan tujuan untuk mengukur seberapa jauh tingkat pengetahuan kader. Dari hasil pretest diketahui bahwa sebagian kader belum mengetahui batasan-batasan faktor risiko penyakit tidak menular seperti berapa batasan kolesterol darah total yang normal atau tidak normal masih banyak yang salah menjawab.

Tujuan dilaksanakannya pelatihan ketrampilan untuk meningkatkan kapasitas kader dalam memberikan pelayanan (Rufiati et al., 2011). Para kader melakukan kegiatan penimbangan/pengukuran belum sesuai dengan standar-standar pengukuran antropometri sehingga hasil yang diperoleh dari penimbangan/pengukuran kurang tepat. Oleh karena itu diberikan pelatihan keterampilan mengenai cara pemantauan yang benar meliputi standar penimbangan berat badan, mengukur tinggi badan, kemudian dari hasil penimbangan/pengukuran dicatat dalam buku monitoring faktor risiko PTM dan menginterpretasikan tren hasil pemantauan setiap bulan kepada peserta posbindu yang dikemas dalam konsultasi gizi di meja ke lima posbindu.

Hasil pengamatan pengabdi pada saat pelaksanaan posbindu para kader masih melakukan kesalahan saat pengukuran, seperti saat mengukur lingkar perut mengukurnya tidak di tepat pusar. Kemudian tidak ada kader yang berani melakukan pengukuran menggunakan alat autocheck (gula darah, kolesterol, asam urat) sehingga selama ini yang melakukan pengukuran adalah bidan desa. Lalu pada saat melakukan penimbangan berat badan juga masih melakukan kesalahan karena kader melihat dari samping, tidak dari atas padahal menggunakan timbangan badan yang manual.

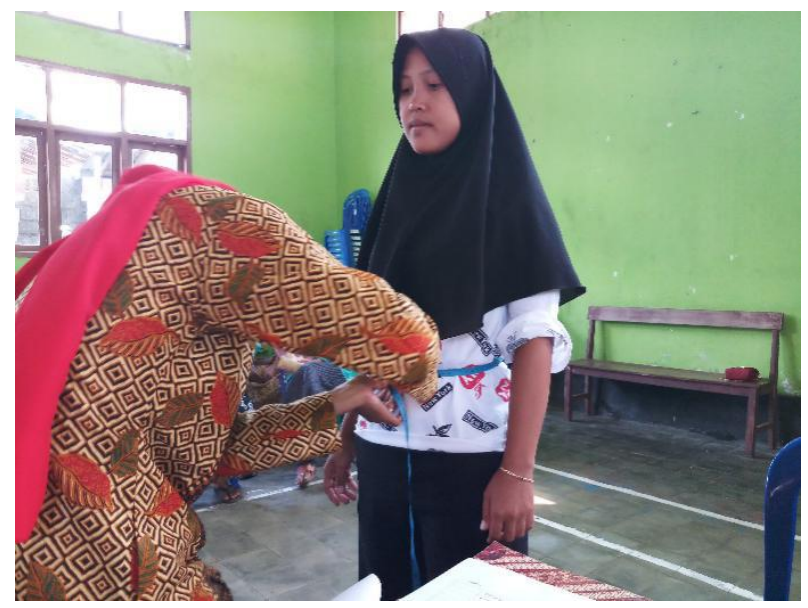

Gambar 4. Kesalahan dalam melakukan pengukuran lingkar perut 


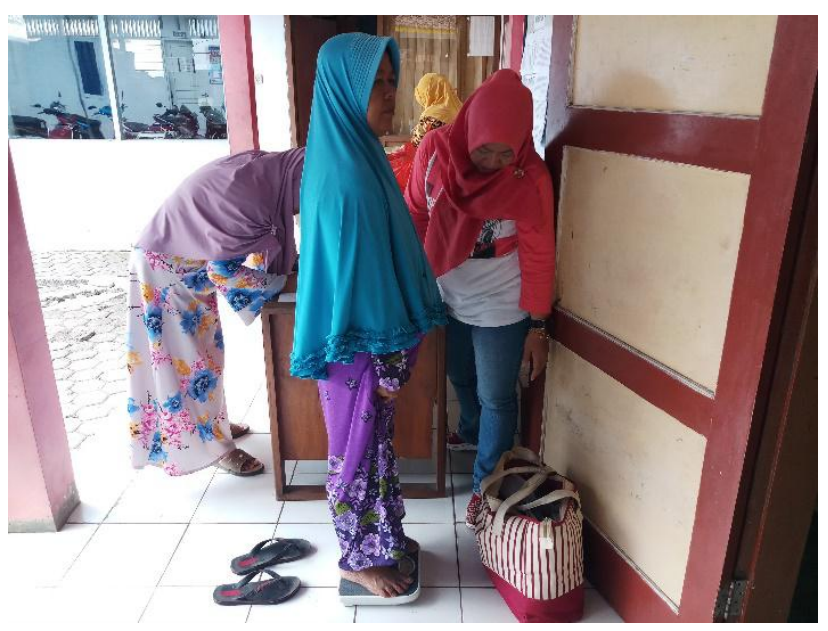

Gambar 5. Kesalahan dalam membaca hasil penimbangan

Pada pertemuan kali ini tim pengabdi mengadakan pelatihan keterampilan mengenai cara pengukuran antropometri yang benar meliputi prosedur standar penimbangan berat badan, mengukur tinggi badan, gula darah, kolesterol total, lingkar perut lalu mencatat dan menginterpretasikan tren hasil pengukuran setiap bulan yang dikemas dalam konsultasi gizi.

Praktik pelatihan pertama didampingi oleh Yovita Puri Subardjo, S.Gz., MPH., RD mengenai monitoring faktor risiko penyakit tidak menular pada masyarakat di Posbindu Sehat Mulia III Karanggintung dan cara konsultasi gizi yang baik dan benar. Para kader diajarkan cara mengisi buku monitoring faktor risiko penyakit tidak menular supaya pencatatan rapi dan dapat diinterpretasikan setiap bulannya.

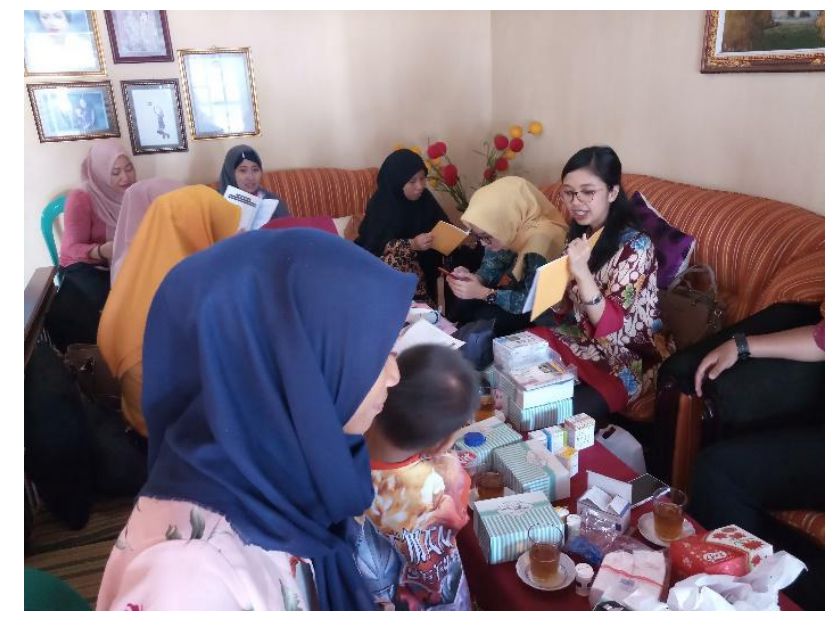

Gambar 6. Praktik mengisi buku monitoring faktor risiko PTM

Praktik pelatihan keterampilan kedua didampingi oleh Annas Sumeru S.Kep, Ns., M.Kep., Sp.Kep. MB yang memberikan keterampilan tentang teknik dan prinsip menggunakan alat autocheck. Para kader posbindu selama ini belum bisa menggunakan alat autocheck, sehingga pada pertemuan kali ini seluruh kader diwajibkan mencoba menggunakan alat autocheck. Dari hasil pelatihan terdapat satu kader yang cukup terampil dalam menggunakan alat autocheck sehingga diharapkan kader tersebut dapat melakukan pengecekan darah pada saat kegiatan posbindu berlangsung. Hal ini sesuai dengan pendapat Afiatin (2013) yang menyatakan bahwa pelatihan merupakan salah satu cara yang tepat untuk pengembangan sumber daya manusia. Pelatihan dilakukan oleh mentor atau fasilitator dengan cara memberi kesempatan belajar yang bertujuan untuk pengembangan individu. 


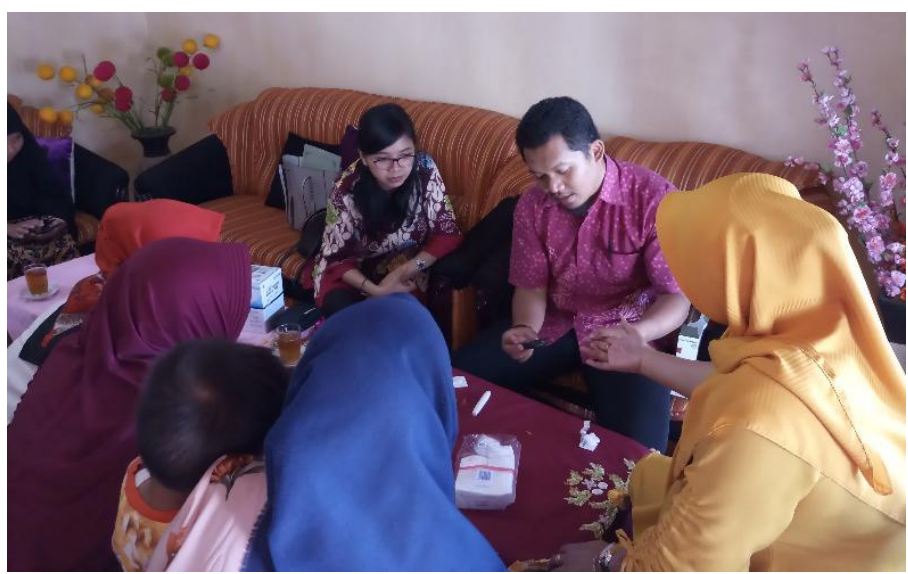

Gambar 7. Praktik keterampilan menggunakan alat autocheck

Selain keterampilan diatas, para kader juga diajarkan mengenai cara mengukur lingkar perut yang benar dan cara mengukur serta membaca spigmomanometer digital. Para kader diberi pengetahuan mengenai batasan tekanan darah yang normal adalah $<140 / 90$ dan tidak normal jika $\geq 140 / 90$. Lalu kader juga diberi keterampilan mengenai cara mengukur lingkar perut yang benar menggunakan pita metlin.

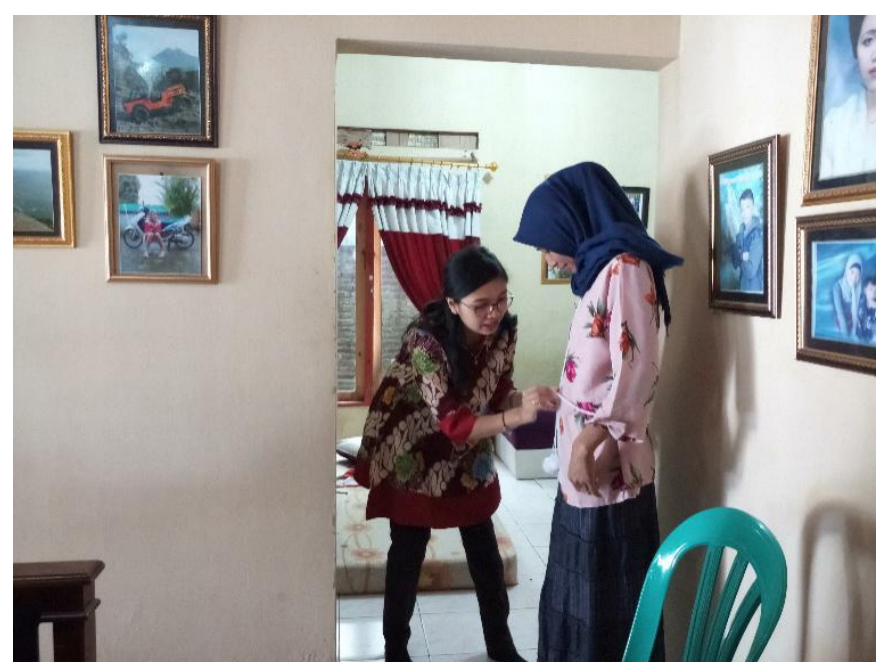

Gambar 8. Praktik mengukur lingkar perut yang benar menggunakan pita metlin

Pada akhir pertemuan dilakukan pemberian sarana dan prasarana pelayanan untuk kegiatan di posbindu. Pemenuhan jumlah dan macam sarana dan prasarana yang dibutuhkan dalam rangka pemantauan faktor risiko PTM diharapkan dapat memudahkan para kader dalam pemantauan dimana hal ini akan berdampak pada optimalisasi posbindu dalam deteksi dini faktor risiko PTM. 


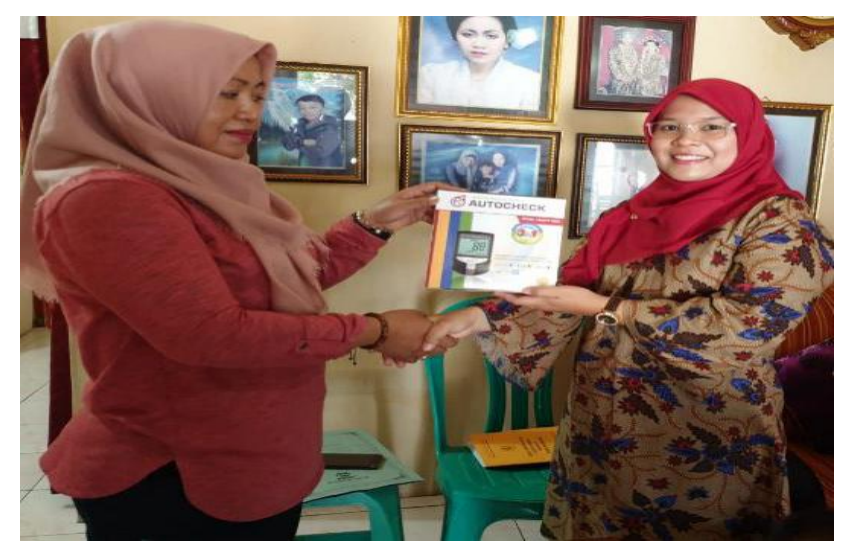

Gambar 9. Pemberian sarana dan prasarana kepada kader Posbindu

\section{d. Pendampingan kegiatan Pelaksanaan Posbindu}

Evaluasi pelatihan dilaksanakan ketika kegiatan Posbindu berlangsung. Kegiatan Posbindu Sehat Mulia III rutin dilakukan setiap bulan pada minggu pertama. Pelaksanaan posbindu setelah diberikan pelatihan dari tim pengabdi Unsoed cukup kondusif, pada saat kegiatan berlangsung seluruh kader sudah terampil pada tugasnya masing-masing atau dengan kata lain kelima fungsi meja di posbindu sudah mulai aktif. Berdasarkan hasil pengamatan terjadi peningkatan keterampilan yaitu hampir seluruh kader tergolong benar dalam melakukan pengukuran, pengisian buku monitoring dan sudah dilakukan sesi konsultasi. Salah satu kader juga cukup percaya diri dalam melakukan pengukuran menggunakan alat autocheck. Sehingga dapat disimpulkan bahwa pelatihan dapat meningkatkan keterampilan dan pengetahuan para kader (Evita et al., 2013).

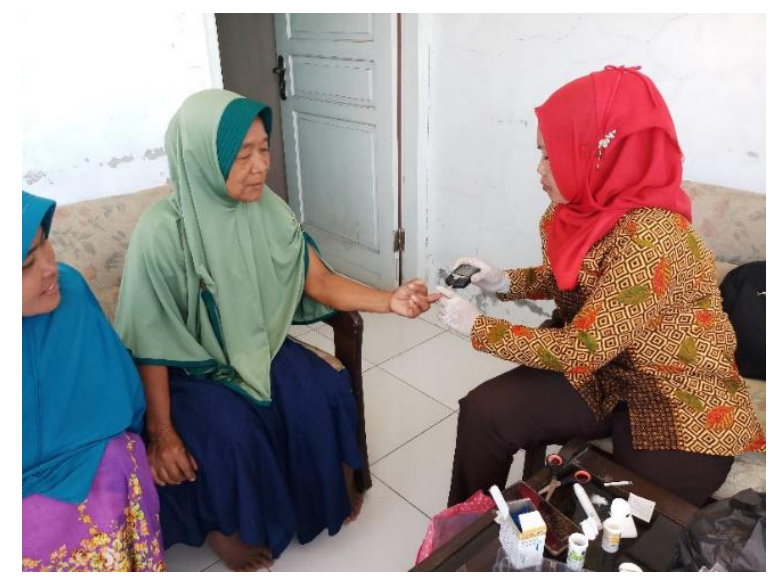

Gambar 10. Kader cukup terampil dalam melakukan pengukuran

Pada akhir kegiatan pengabdian, pengabdi melakukan evaluasi dengan berdiskusi para kader terkait manfaat dan kekurangan pelaksanaan kegiatan ini. Dari hasil evaluasi para kader merasa sangat puas dengan kegiatan yang diadakan oleh tim pengabdi, selain mendapat banyak pengetahuan dan keterampilan, kader juga cukup senang dengan diberikannya beberapa fasilitas untuk menunjang kegiatan posbindu sehingga berdampak pada optimalisasi posbindu Sehat Mulia III dalam deteksi dini faktor risiko PTM. 

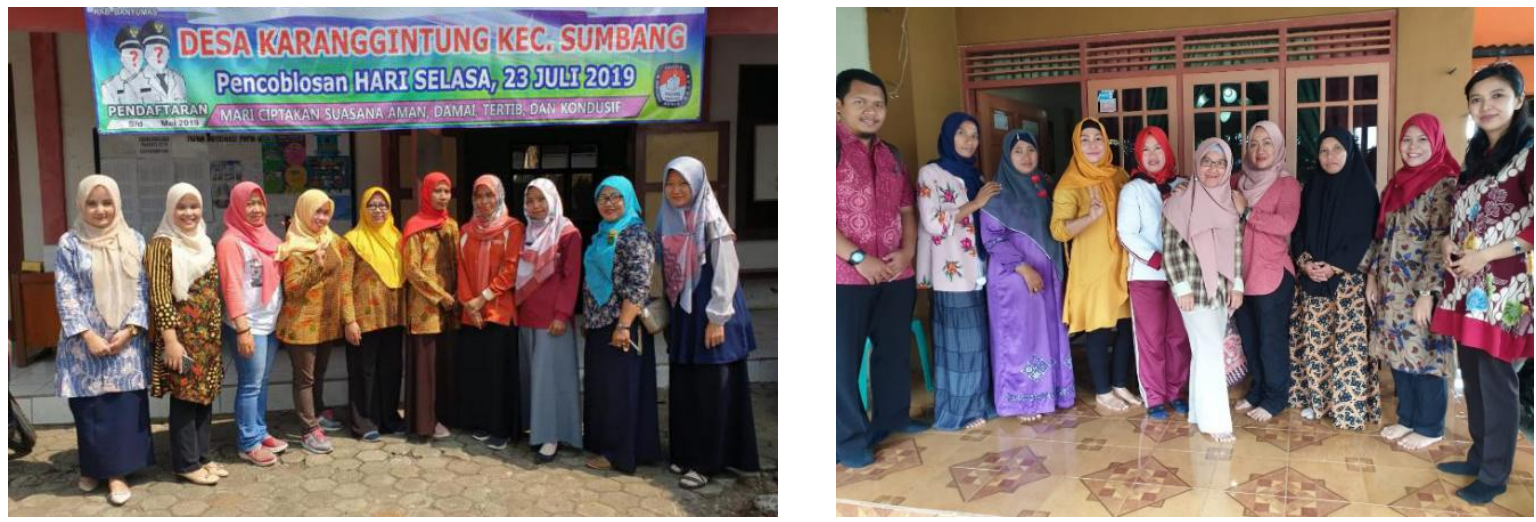

Gambar 11. Tim pengabdi dan para kader Posbindu Sehat Mulia III

\section{KESIMPULAN}

Pelaksanaan pelatihan di Posbindu Sehat Mulia III Desa Karanggintung Kecamatan Sumbang Kabupaten Banyumas dapat meningkatkan kompetensi kader terlihat dari meningkatnya pengetahuan dan keterampilan para kader sehingga akan berdampak pada optimalisasi monitoring faktor risiko penyakit tidak menular secara dini.

\section{DAFTAR PUSTAKA}

Afiatin, T. 2013. Mudah dan Sukses Menyelenggarakan Pelatihan: Melejitkan Potensi Diri. Kanisius: Yogyakarta.

Balitbangkes, 2013. Riset Kesehatan Dasar Riskesdas 2013. Jakarta: Kemenkes RI.

Direktorat Pengendalian PTM, 2014. Program PTM. Diakses dari http://pptm.depkes.go.id/cms/frontend/?p=progptm pada tanggal 6 Desember 2018.

Effendi, N. 2008. Dasar-dasar Keperawatan Kesehatan Masyarakat. Jakarta: EGC.

Evita, D., Mursyid, A., Siswati, T. 2013. Pelatihan meningkatkan pengetahuan dan keterampilan kader puskesmas dalam penerapan standar pemantauan pertumbuhan balita di Kota Bitung. Jurnal Gizi dan Dietetik Indonesia. 1(1): 15-21.

Hida FM., Mardiana. 2011. Pelatihan terhadap keterampilan kader posyandu. KEMAS 7 (1) : 22-27.

Paramita, A., Kristiana, L. 2013. Teknik Focus Grup Discussion dalam Penelitian Kualitatif. Buletin Penelitian Sistem Kesehatan. 16 (2): 117-127.

Rufiati, AM., Bambang Budi Raharjo, Fitri Indrawati. 2011. Pengaruh metode permainan Find Your Mate Terhadap Pengetahuan Kader Posyandu. KEMAS 6 (2) : 113-119. 